\section{Typographers' Inn}

Peter Flynn

\section{Titling and centering}

I forget who first pointed it out, but one of the earliest pieces of advice I remember was to break title lines according to sense when they are set centered. Anyone who wants to glance at their organization's noticeboards can see the effect of not knowing this: how often do you see isolated words on lines by themselves, as if they were an afterthought.

Breaking according to sense means reading the title and seeing where the natural pauses in rhythm and meaning occur, and making breaks there. Failing to do this not only means the title is harder to read, because the brain has to struggle to join back together phrases or words which should not have been split up, but also, depending on the way it has been broken, you can sometimes even end up with a humorous misinterpretation.

Many people will be familiar with this phrase

\section{PARIS \\ IN THE \\ THE SPRING}

in which 'the' is duplicated. That is deliberate, as was the poster a colleague at the London College of Printing designed for an exhibition called 'Things aren't what they seem to be'. The opportunity was too good to pass up (Figure 1).

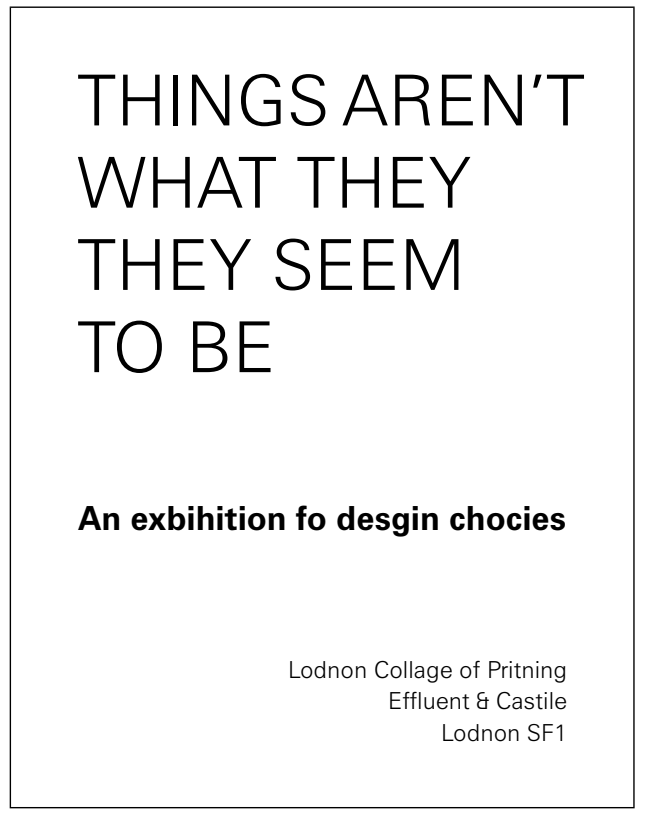

Figure 1: Student poster, c.1975, author's reconstruction from memory
Alas, I can only reconstruct a rudimentary copy here. For those unfamiliar with London, the Elephant and Castle was then a rather run-down district on the south bank, still showing the scars of WWII bombing and the ghastly New Barbarism of the 50s and 60 s reconstruction.

More recently my local convenience store was advertising

HALF-PRICE
DESSERTS FROM
OUR IN-STORE
BAKERY

It's only ephemeral, but it would have been more readable, especially to passers-by, if it had read

\section{HALF-PRICE DESSERTS FROM OUR IN-STORE BAKERY}

Closely related to this is a combination of unfortunate circumstances which I first saw on the spine of a book. The front cover used the same face for author and title, but in different colors: a mauve for the author and a washed-denim for the title (Figure 2).

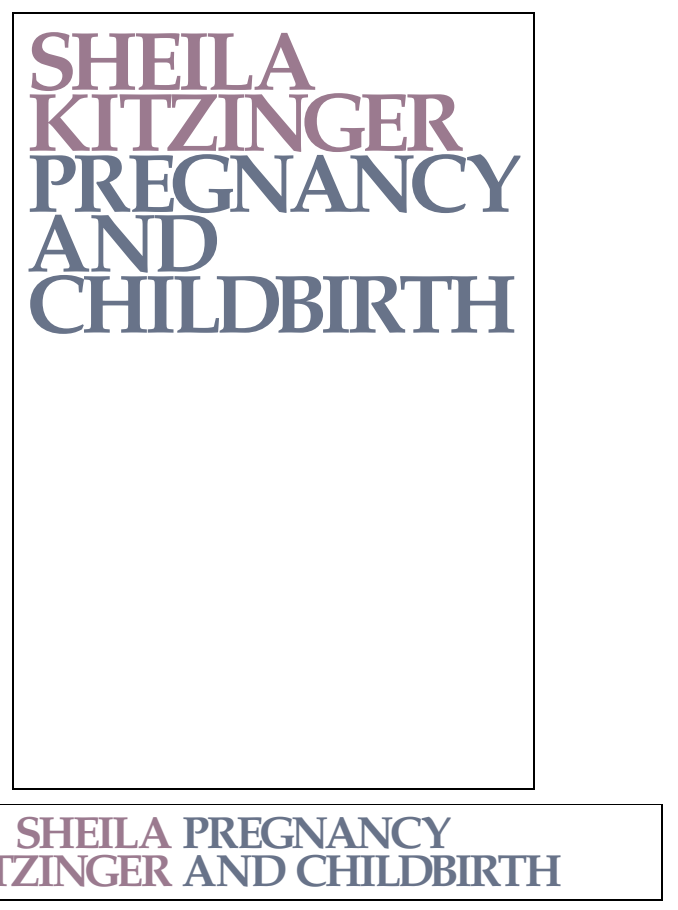

Figure 2: Front cover and spine (reconstruction, omitting detail)

The spine used the same colors and typeface, but arranged with the author name to the left, two lines flushright, hard up against the title to the right, two lines flushleft. The unfortunate combination of the close spacing and the fading of the colors over 
time leaves one with the impression that this was Sheila Pregnancy's Kitzinger and Childbirth.

A close contender is the copy of Stieg Larsson's The Girl with the Dragon Tattoo which I was given for Yuletide. The spine almost leaves you with the impression that is it THE GIRL WITH THE STIEG by DRAGON TATTOO LARSSON.

\section{Beaten into submission}

Some years ago I signed up to do a late-life part-time $\mathrm{PhD}$. It's been a long time a-growing, but it's getting somewhere near fruition. Which is all well and good, and nothing to do with this column, except that as a by-product, I was obviously going to produce the thing using $\mathrm{AT}_{\mathrm{E}} \mathrm{X}$. My university didn't even have a Word template for theses, let alone a thesis document class for $\mathrm{AT}_{\mathrm{E}} \mathrm{X}$, so it equally obviously behove me to write one.

I made a start, initially for my own benefit, but as this was a part-time task slaved off another parttime task slaved off a full-time task, it tended to get quietly ignored while I fiddled with more burning issues like research and a day job. My patient and long-suffering co-students were repeatedly told 'it's on its way', but it took until last summer for something usable to appear. I started with the crufty and encrusted code that I had been working with, chipped off the barnacles, oiled the insides, fixed the broken bits, added the requisite bells and whistles, polished the outsides - and then had to start thinking about appearances.

The university's regulations are simple to the point of being simplistic: one-sided; a $4 \mathrm{~cm}$ left-hand (binding) margin, $3 \mathrm{~cm}$ everywhere else; a 'plain' typeface (that is, not ornamental or decorated); the text double-spaced or $1 \frac{1}{2}$-line-spaced; some specific items on the (centred) title page; a table of contents, Declaration, and 200-word Abstract. That's about it, so the detail was basically up for grabs by each student. The Graduate Studies Office, which deals with thesis submission and reception, do in fact impose other rules, but these are so obvious and so rarely broken that they are not usually mentioned (like it has to be printed in black on white paper).

I'm not a graphic designer nor a professional typographer nor even a typographic designer, but I am aware that working to a very loose brief is in some ways harder than working to one too tight. It's also axiomatic that simplicity is best when dealing with a functional document whose primary purposes are to act as a record of your findings and to convince your Extern that you are safe to let loose on the world of research. However, the more I looked at the largely pragmatic and temporary choices I had made for my drafts, the more I realised the dangers of allowing the technology to dominate the design: just because $\mathrm{AT}_{\mathrm{E}} \mathrm{X}$ (or whatever system) can do something, doesn't mean that you have to do it. One of the pitfalls of having spent a lifetime working with computer documentation is that there is a tendency for all document content to end up looking like The TEXbook, regardless of the page layout and the typeface.

As it turned out, I made a lot of cuts and very few additions. I had in fact just been experimenting with different layouts for floats before deciding that the marginal improvement in balance between float and the surrounding text wasn't worth the additional weight of code, so I carried this principle over to the rest of the class.

The document class loads the default report with the options oneside, 11pt, a4paper, thus the only variations are those required by the regulations, and a few which I have seen fit to impose on myself. There are discussions about printing two-sided to save trees, but with electronic submission imminent, the argument appears to be moot.

Layout: a separate title page and one-sided imposition are mandated; A4 is the only paper size, although it will allow Letter, in case students with US funding agencies or sponsors need a copy to fit their filing system. It was not hard to fix the text area so that it works acceptably if not optimally on both sizes of paper.

Type size: currently fixed at 11pt - I would have preferred $12 \mathrm{pt}$, because the important people reading it (supervisor, Prof, Extern) tend to be much older than the student, and therefore have suboptimal eyesight, but 12pt does increase the page count significantly. I need to experiment with the balance between line-spacing and type size for this exact line-length.

Line-spacing: double-spacing makes the thesis far too many pages, although it has a legitimate purpose for drafts, where readers appreciate having the space to scribble comments. Lineand-a-half looks about right, but there's nothing to stop the student overriding this. A 10pt setting is clearly too small for the length of lines on an office-size sheet of paper with the given margins without resorting to double line-spacing or more.

Typeface: for those including a significant amount of mathematics, the scope is very limited, and I suspect most will stick to CM or Times. Otherwise it's up to the author, within the confines of the regulations. I used Charter, because I find it reads easily in very long documents. 
Justification: I made the whole document default to \raggedright for several reasons: a $\mathrm{PhD}$ thesis is not a book for printing to publishers' standards; it's not good for an author to spend a lot of time fiddling with manual reformatting to 'make things fit'; and the line-length is already too wide for comfortable reading. It's not an ideal choice, so I am providing an option to switch back to justified setting for those who feel they can deal with it. I posted about this on comp.text.tex while writing this column, so I'm still open to suggestions.

Paragraph spacing: The default uses the parskip package, so there is no indentation, and about one baseline's space between paragraphs. I did provide an option to switch back to indented, unspaced paragraphs at the insistence of some users who wanted a more book-like layout.

The bulk of the class file is taken up with options for the preselection of the School or Department and the class of Degree using abbreviations as options, so that the title page can be composed correctly. The code list is refreshed annually from the Registrar's database of the graduate courses on offer, so authors still finishing degrees in disciplines no longer on offer to new students, or in schools or departments no longer operating solo, have to be catered for by preserving the validity of old options.

The design of the title page is straightforward, and largely mandated by the prescribed contents: title, author, department, degree, supervisor, date, and so on, in varying sizes, and centred.

Some things in the text body, however, I did change, simply because the default $\mathrm{ATT}_{\mathrm{E} X} \mathrm{X}$ layout naturally reflects the typographic habits of US book design of the 1970s and 80s, and I feel it is time to move on.

Front matter: Apart from providing environments for the Dedication and Acknowledgments, there is a generic \prelim command for optional preliminary sections like admonishments, standards certification, and terminologies, not part of the thesis proper. It is basically a \section* command, except that it also adds itself to the ToC.

For the ToC, LoF, LoT, Bibliography (and Index, if anyone wants one), the heading is at section level, starting a new page, not (by default) at chapter level. These are not divisions of chapter status, perhaps excepting the Bibliography, and it is usually wrong to accord them that format.

The presence of a LoF and LoT is automated, using a Boolean switch added to the . aux file at the end if either the figure or table counter is non-zero. This can be overridden if, for example, an author has only a very few figures or tables.

Description lists: $\mathrm{HT}_{\mathrm{E}} \mathrm{X}$ 's default, as with this list, is to format the topic heading run-in to the text. This is idiosyncratic, and nowadays unusual outside the dictionary format. The separate-line format, as exemplified in HTML's <dt> element type seems to be expected by readers and writers alike, so I changed the \descriptionlabel to use a \parbox to give the topic heading a line or lines to itself. This also overcomes the standing bug in $\mathrm{ATEX}_{\mathrm{E}}$ whereby very long labels fail to break correctly at the end of a line.

Quotations: The quotation environment now has an optional argument for the key value for the citation of the quote, which is printed flush right after the text. A similarly-implemented epigraph environment does the same for authors wanting introductory quotes for their chapters.

So all in all, I hope it stays a commonplace and unobtrusive layout, which is how a thesis design should be: it's the student's arguments that should stand out, not the typography. It's available within the university on pilot, and will be released into the wild once I'm satisfied that it's as student-proof as needed.

Currently I am still recommending BIBTEX to users: we have a lot of them still depending on old .bst files, and until I can get to deal with these, I'm holding back on recommending biblatex.

\section{Afterthought}

I need to update my online book, Formatting Information to reflect $\mathrm{TEX}$ Live 2011 and a lot of package updates. There are also some substantial parts that have been superseded by technology - it doesn't need a whole chapter on how to print from a DVI or PS file any more.

If you have read or used it in teaching, I'd be grateful for suggestions for improvement (http:// latex.silmaril.ie/formattinginformation).

And just as we go to press, I have started to see badly-broken display lines in flush-left text, not just in centred text. Grrr.

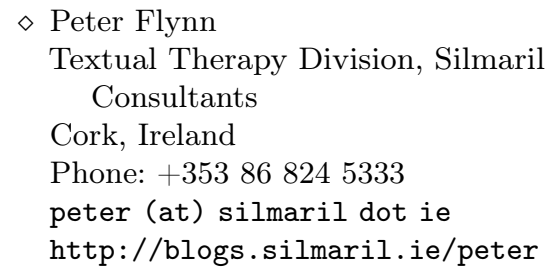

